\title{
Factors Fostering Shadow Economy Performance in Poland and Lithuania during 2000-2019
}

\author{
Andrzej Buszko \\ University of Warmia and Mazury in Olsztyn \\ M. Oczapowskiego 2 str., 10-900 Olsztyn, Poland \\ E-mail.buszko@uwm.edu.pl \\ cross'ref $^{\text {http://dx.doi.org/10.5755/j01.ee.33.1.24944 }}$
}

\begin{abstract}
This study relies on a calculable and essential analysis of a statistically oriented regression model. Ninety-five variables taken into consideration in this research were grouped into four categories. The first category covers the general macroeconomic situation, the second is devoted to crime, the third is formed by characteristics of income and living conditions, and the fourth one applies to the taxation system. The Multiple Indicators Multiple Causes (MIMIC) model was employed to measure the level of shadow economy in Poland and in Lithuania during 2000-2019. The MIMIC model depends on Structural Equation Models. The MIMIC approach allows one to assess shadow economy as a latent variable. The observed factors are government employment/labor force, tax burden, subsides/GDP, social benefits paid by government/GDP, self-employment/GDP, and unemployment rate. The Pearson correlation index was used to size up the correlation between independent variables, and Kolmogorov-Smirnov (KS) test for normality of residuals was applied. In both countries, factors affecting the shadow economy performance show great similarity. The shadow economy development in Poland and in Lithuania is fostered by many different factors, related to, but not limited to, the general macroeconomic situation. In fact, the economic situation is associated with the standard of living, income as well as the crime rate. Important factors are associated with the taxation system. The results demonstrate that the regression model can be used to predict the shadow economy development and performance in Poland and in Lithuania. Such information facilitates taking adequate steps in order to minimize the shadow economy level in both countries. Such implications are very useful for decision makers in shaping the legal and economic progress in both countries.
\end{abstract}

Keywords: Shadow Economy; Factors; OLS Model; MIMIC Model; Taxation; Crime; Income and Living Conditions; Economic Situation; Poland; Lithuania.

\section{Introduction}

Shadow Economy (SE) is a phenomenon which exists in any country; it just varies by its level and category. Shadow economy has impact on the overall economic situation. That is why societies investigate this economic category and must take control of it. Schneider and Enste (1999) evaluate the level of shadow economy to be between $7.9 \%$ of the official Gross Domestic Product (GDP) in the United States and $66.4 \%$ in Georgia. On average, shadow economy reaches the level of $15 \%$ of the official GDP in the Organization for Economic Cooperation and Development (OECD) countries, while the approximate level in other parts of the world is around $35 \%$ (Buehn et al., 2013). The level of shadow economy in Poland is still high (ca. $24 \%$ of GDP), and it is distressing economic performance. The roots of shadow economy in Poland have long tradition. During planned economy, the constant shortage of consumer products and services created favorable conditions for the development of shadow economy. Market gaps were filled by shadow economy. In this way, shadow economy activities gained quite broad acceptance in the society. The transformation period did not substantially reduce the level of shadow economy. Nearly all efforts to eliminate shadow economy have proven to be ineffective. The crucial issue is linked with the type of business activity, which can be universally divided into two categories: legal and shadow economy one. Companies have the choice: they can perform legally or in shadow economy. If we assume that business entities are not willing to operate in shadow economy (for example because of high ethics norms), then more space for legal action will be foreseen. Such a situation will even be hard to change by weak institutional solutions.

The origins of shadow economy are mostly identified. According to the literature review and research studies, the most typical factors fostering the shadow economy are related to:

- level of taxation and tax morale (Buehn et al., 2012)

- inappropriate labour market regulations (Rosser Jr., Rosser \& Ahmed, 2000);

- complicated and contradictory legal system (Curti et al., 2015);

- unemployment rate (Maloney \& Mendez, 2004);

- level of corruption (Dreher \& Schneider, 2006);

- social security contributions (Schneider \& Williams, 2013);

- quality of public institutions (Andersen et al., 2007;

- national culture (Buszko, 2019);

- structure of the population's income (De Soto,2000);

- inefficient market exit (Giuliano, Ruiz-Arranz, 2009). 
Kabaj implies that one significant determinant of shadow economy is a high unemployment rate (Kabaj, 2009). This opinion is generally true one, but should be clarified. During the recession period, the unemployment rate increases and the jobless are absorbed by the shadow economy. During prosperity, the unemployment rate decreases. This is because of the higher demand for labor force in legally operating industries. The motive why individuals might decide to become active in the shadow industry is the restrictions set up by the government (Frey, Week, 1982). There is quite an interesting fact related to national culture, which can be interpreted as a common set of principles, believes, widely accepted that influence human behavior. Disciplines, professions, and institutions in modern bureaucratic society cultivate and transmit cultural values and meanings. That is why shadow economy can grow in some countries, while in others it remains on a more or less same level or slowly decreases. Greek example is a typical case of the shadow economy supported by the national culture. Greek national culture encourages the existence of shadow economy, which has spread all over the country. Even the government officials used to prepare fake reports on the Greek budget deficit in order to be granted higher EU support. Furthermore, shadow economy has been promoted by the widespread horizontal and vertical corruption (Katsios, 2006). Whenever society justifies certain activity, it is far more easier for individuals to participate in it. A high level of justification can also be interpreted as displaying the level to which citizens are actually involved in the shadow economy motion. Whenever more citizens take part in the shadow economy activity, the higher level of its acceptance is noticed. This relation was particularly observed in the labor market (Zukauskas \& Schneider, 2016).

Internationalization of business activity may change companies attitude to the way of cooperation, especially taking into an account institutional order (Sekliuckiene, 2017). Whenever entrepreneurs operate on wide range scale their culture supposed to be quite flexible in order to cope with dissimilar partners.

Understandably, numerous different organizational cultures may occur in the same main national culture. Even in well-developed, market-oriented countries with grounded democracies and with a low level of shadow economy, there are still some companies that accept shadow economy activities, but at the same time there are enterprises that reject to collaborate with shadow economy animators. Loayza et al. (2006) made a very good observation that countries with better institutional solutions pursue to design regulatory business surroundings unaffectedly aimed to expand economic conditions rather than prerogative for just a few interest groups. They are also more likely to enforce regulation in a transparent way reducing the possibility for uncertainty decisions and corruption attitude. The effects of shadow economy are plentiful and unavoidable. It decreases government revenue and violates budget distribution and distorts economic indicators (development, employment, revenue, creativity, innovation, effectiveness etc.), in that way in depraved way influencing the public sector as well as individual inducements. Dell'Anno, Gomez-Antonio, Pardo (2006) noted that shadow activity has been greatly increased in the OECD countries in recent years.

\section{Literature Review}

Shadow economy shows some performance in each economy, although it varies in its level and category. In many cases, shadow economy creates a puzzling scientific problem. This is due to the fact that there are many different definitions of shadow economy in the literature. Different definitions make different economic category. That is why researchers can obtain different results even though they focus on the same problem. This is because they may measure and investigate dissimilar types of economy. In the literature, the following terms are applied to characterize shadow economy: underground, informal, illegal, grey zone, not registered, offbooks, night economy, and moonlight, under reporting, or even black or immoral white economy. Generally, those definitions are considered as synonymous. But in fact there are quite important differences among them.

Shadow economy has been increasing in both nominal and real terms much more quickly than legal economy. However, in some countries, a decrease of shadow economy is noticed. In the post-war period, the progress of shadow economy was not unchanging, i.e. its growth rate and its relative size have fluctuated significantly, which can be even understood as a shadow economic business or growth cycle. In a long term outlook, the development of shadow economy and legal part of national economy have not automatically been parallel. In some cases, the progress of shadow economy was contrary to the official economy's growth cycle. It seems to be flourishing every time legal economy reveals secular stagnation or recession symptoms (Cassel, 1984). Following Dell'Anno's approach, modifications of shadow economy are very visible. For example, informal production refers to specific business activity characterized by a low level of organization, little capital involvement, predominantly based on occasional jobs. Dell'Anno pointed out craftsmen, salespersons without licenses, farm workers and home staffs. Generally it could be stated that all illegal production as well as the sales of it is banned by law. Included in this area are also productive activities carried out by unauthorized operators. Underground production may be fully legal one but due to the economic reasons these activities can be carried out with the deliberate desire to avoid taxes and social contributions. Such activity is characteristic in construction business, agriculture or entertainment business That why it proves to be difficult to calculate. Researches quite often size up different aggregates and therefore a more consistent approach from both the theoretical and empirical perspective is required (Dell'Anno R., 2007). Some illegal enterprises, however, operate at a large range. The wider the range of activity and the more associates attempt to be involved, the greater the probability that illegal businessmen thrive outside the logistical backing thanks to transactions with legitimate third parties. The scale of such operations can increase beyond the threshold when legal entrepreneurs feel the need to justify their way of doing business (Lampe, 2015). Shadow economy has sound performance and cannot be minimized even by restricted and severe law. In evaluating the impact of regulation, it is important to contemplate that both the quality and the quantity of regulations and institutions can act as a stimulus. If the quality of the institutions and solutions is poor and the regulation density is high, firms try to escape from this 
regulatory framework by switching their business to a shadow economy framework (Enste, 2010). Noteworthy, a growing shadow economy can be labeled as a response of individuals and companies who feel exploited by the government. It is possible that shadow economy is simply an unintended consequence of voters' choice. Otherwise, it is reasonable to claim that shadow economy is an intentional consequence of a policy designed for informal groups, or even with intent to lower labor costs for preferred shadow industries. However, the decisive causality of the policies that encourage shadow economies is not deeply studied (Wiseman, 2013). Furthermore, shadow economy is quite closely connected with crime. Criminal acts make an impact on shadow economy's development. This is due to relativeness. Crime is generally not accepted by society. If the crime rate is high, shadow economy seems to be a relatively "innocent" activity because it will not harm individuals directly so much. Secondly, offenders search possibilities for cooperation with shadow economy animators. They would like to have "support" in selling stolen goods, distribute fake products or traffic narcotics (Cook, 1986). Shadow economy has been fostering banking activity quite substantially. The research by Misiukiewicz and Dec (2015) provided interesting information on different types of black-market loans. In some countries like China, Italy and Poland, illegal lending has become a serious problem. Gobbi and Zizza (2012) investigated the relationship between illegal activities and financial expanding. They found a strong negative impact of the share of irregular employment on outstanding credit to the private sector. Another very important issue in the context of shadow economy acceptance is populism. Populism may be regarded not only as political or social but economic phenomenon as well. It refers to a "normal man", typically not well-educated, being disappointed with his material status and perceives cultural threats from those with different values in the country or overseas. "Normal man" is confronted with "establishment elites" in positions of power. Populist supporters strongly believe that government does not work effectively for them. Such a situation makes the chance put strong leaders into the power. Populist leaders are usually aggressive rather than cooperative and exclusive rather than inclusive. As a result of such a case, struggles tend to arise between conflicting blocs (usually political and the economic, socially left versus the right), both within the country and even among countries. These conflicts characteristically become progressively more forceful in self-reinforcing ways. But one should remember that conflicts often cause disorder and chaos in the society (Dalio et al., 2017). Disorder simply makes a space for shadow economy's expansion. On the other hand, populist rulers try to fulfill their promises and expand the budget spending. Thus, they expand the budget deficit and, in the long run, create market gaps. Those gaps are or will be filled by shadow economy. During populist times, managers' entry into politics proves to be very harmful for legal activity. Managers strongly believe that they can bring benefits to themselves and to the firm. On the other hand, such managers' decisions are not ambiguous regarding when and why a politician would join a firm, and when this event would be corruptive. It is clearly easier in populist states for a politician to be a member of the board if the company is stateowned. Nevertheless, not all politically chosen managers or members of boards of state-owned companies are corrupt, but they will anyway obey the political party rulers' instructions. If they try to be independent, they will be replaced, sooner or later, by individuals more compliant to cooperate (Domadenik et al., 2016).

\section{Methodology Approach}

The level of shadow economy was calculated by the MIMIC method. This approach is recognized, accepted and widely applied in such cases. The general idea was adopted from Dell'Anno's examination of shadow economy in Portugal. The MIMIC calculation is employed by other well-known researches, like Dell'Anno, R., GomezAntonio, M., Pardo, A. (2007), Schneider, F., Enste, D. (2000). The general idea of measurement of shadow economy is presented in figure 1 .

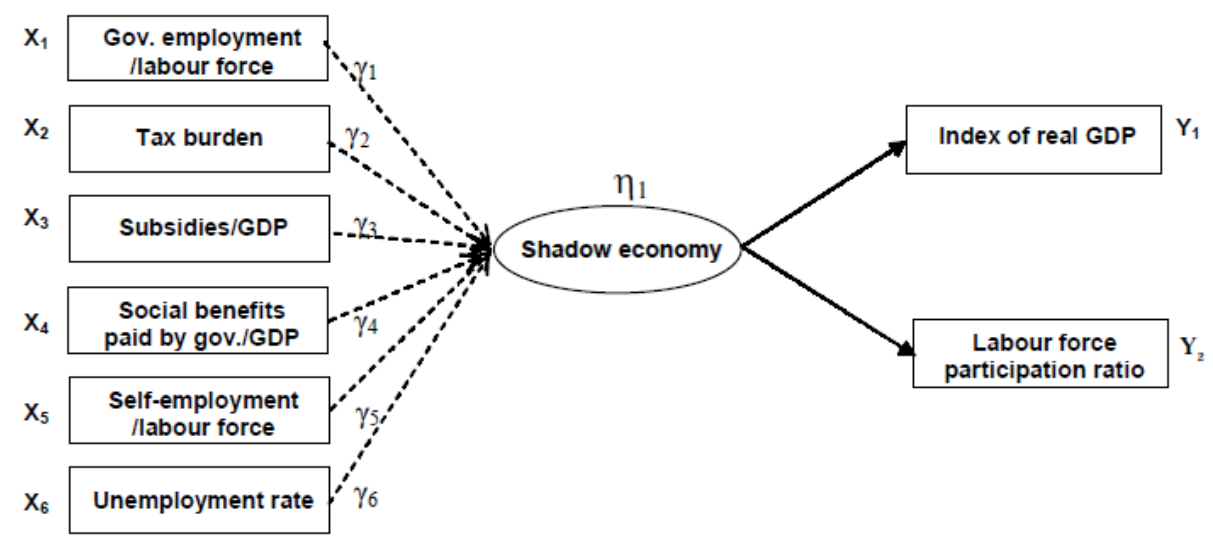

Figure 1. Determinants of Shadow Economy

Source: Dell'Anno R. The Shadow Economy in Portugal. An Analysis with the MIMIC Approach. Journal of Applied Economics. 2007 Vol X no 2 November 
The structural equation model consists of statistical relationships among latent (unobserved - the level of shadow economy) and evident (observed) variables. The level of shadow economy was calculated for the years 20102019. The data were obtained from Bloomberg (WECO page), OECD Standardized National Accounts and OECD Labour Force Statistics and GUS (Statistical Yearbook of Poland - Rocznik Statystyczny 2019), and the European Union Statistics on Income and Living Conditions. The survey was carried out by the Central Statistical Office and 16 statistical offices between April and June 2017. The data for 2019 were assessed. The gained data have been accurately purified to avoid redundant statistics. OLS linear regression was used to estimate the value of the dependent variable $Y$, which is the level of shadow economy. Linear regression offers a technique to minimize the sum of the squared differences between the actual value and the forecast for the dependent variable, as well. If the function is correctly linear, then the measurements by least squares are the most likely coefficients to have been used to generate the data. The linear model is as follows:

$$
\mathrm{Y}=\mathrm{a} 0+\mathrm{a} 1 \mathrm{X} 1+\mathrm{a} 2 \mathrm{X} 2+\mathrm{a} 3 \mathrm{X} 3+\mathrm{a} 4 \mathrm{X} 4+\ldots . \mathrm{a} n \mathrm{Xn}+\mathrm{e} i
$$

where :

$\mathrm{Y}$ is the dependent variable, i.e. the shadow economy level; a0, a2, a3, .. an coefficients; X1, X2,.., Xn are the independent variables and $i$ is the error. The Pearson correlation index was used to check the correlation between independent variables. The index was calculated in the following way:

$$
r x y=\frac{\sum_{i=1}^{n}(x i-x s)(y i-Y s)}{\sqrt{\sum_{i=1}^{n}(x i-x s)} \sqrt[2]{\sum_{i=1}^{n}(y i-y s)^{2}}}
$$

Because it is based on the method of covariance, the index is assumed as the best approach of measuring the relationship among the variables assumed in research. It gives information about the magnitude of the correlation, as well as the direction of the relationship.

The Kolmogorov-Smirnov (KS) test for normality of residuals was applied and it was calculated from the formula:

$$
\mathrm{Fn}(\mathrm{X})=\frac{1}{n} \sum_{i=1}^{n} \mathrm{Ixi} \leq \mathrm{x}
$$

$\mathrm{KS}$ is a nonparametric test of the equality of continuous one-dimensional probability distributions that can be used to compare a sample with a reference of probability distribution. Moreover, a null hypothesis is used to test the correlation among variables. The regular error was premeditated by the estimator covariance matrix. Apart from KS-test, the ANOVA test is used to estimate the residual coefficient of the regression model. This test compared two means from unrelated groups of variables using the F-distribution. In the research, the risk of rejecting the null hypothesis was estimated at the level of 0.05 , for which it is statistically significant. Thus, the confidence level is 0.95 and normal distribution reached the level of 1.96. The sum of the squared distances $\left(\mathrm{R}^{2}\right)$ among the observed data and the results from the regression model was applied. The multicollinearity problem was solved by removing highly correlated predictors from the model.

The regression model was tested in four groups of data.

Group 1 refers to Macroeconomic data only (labeled as factors A);

Group 2 refers to Crime data only (labeled as factors B);

Group 3 refers to Income and Living Conditions only (labeled as factors C);

Group 4 refers to Taxation System only (labeled as factors D).

The data cover the period from 2000 to 2019.

Statistica software was applied to calculate the regression and MIMIC formula. The study was conducted on data from Poland and Lithuania. Both countries had belonged to the same model of economy before 1989 and after that time they introduced similar, market-oriented reforms. Although an economic success was noticed, neither country was able to reduce the level of shadow economy performance (Putnins \& Sauka, 2015). Furthermore, these countries are neighbors and patterns of shadow economy activity can be transmitted between them more easily. So far, such research has not been executed, that why it can be regarded as an original approach to identify factors fostering shadow economy in both Poland and Lithuania.

\section{Findings}

Taking into consideration the above mentioned assumptions, figure 1 presents the level of shadow economy in Poland and Lithuania during 2000-2019. In table 1, four models of shadow economy performance and their factors are presented. Those equations were based upon statistically relevant factors and adjusted more than $\mathrm{R}^{2}>0.75$ only. Tables 1 and 2 apply to the Polish case. In table 3, four models of shadow economy performance in Lithuania and their factors are presented. Table 4 presents the statistical values of variables in the regression model referring to Lithuania. 


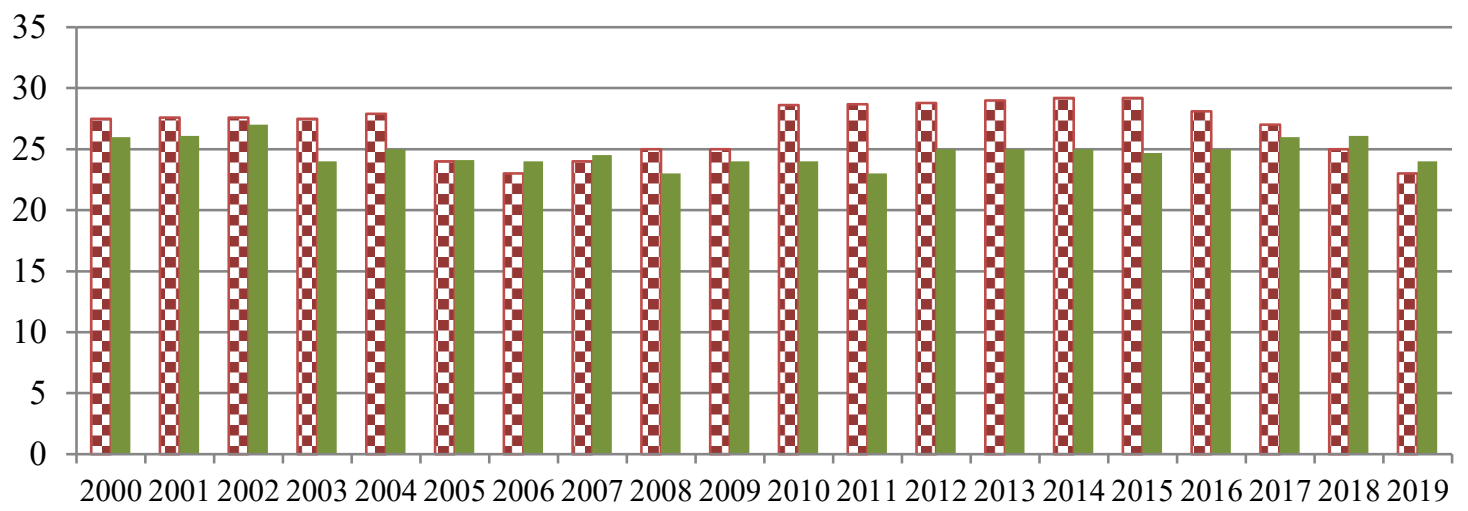

Poland Lithuania -

Figure 1. The Level of Shadow Economy in Poland and in Lithuania During 2000-2019 (\% GDP)

Source: own calculation based upon the MIMIC approach

During 2000-2019, the level of shadow economy in the investigated countries varies. In general, it could be stated that the level of shadow economy in Poland was higher than in Lithuania. Between 2005-2009, the level of shadow economy in Poland decreased, hence it became quite similar to the Lithuanian one, constituting nearly $24 \%$ of GDP.
After 2009 the shadow economy in Poland increased, abut in Lithuania more or less maintained on the same stage ca. $24 \%$ of GDP. Starting from 2015 the level of shadow economy in Poland was reduced - reaching in 2019, $23 \%$ of GDP. In this way the level of shadow economy in 2019 in Poland was smaller than in Lithuania by $1,1 \%$ of GDP.

Table 1

Factors Fostering Shadow Economy Level in Poland

\begin{tabular}{|c|c|c|c|}
\hline No. & Grouped variables & The value of adjusted R $\mathbf{R}^{2}>\mathbf{0 . 7 5}$ & Factors \\
\hline 1. & Group 1, Group 2, Group 3, Group 4 only & n/a & A2, A4, B15, C21, D7, D11 \\
\hline 2. & Group 1 Group 2 Group 3 together & 0.7782 & A2, A4, B15, D3, D,11 D21 \\
\hline 3. & Group 2 with Group 3 and 4 together & 0.8311 & $\mathrm{~A} 2, \mathrm{~A} 4, \mathrm{~B} 15, \mathrm{C} 21, \mathrm{D} 3, \mathrm{D} 7, \mathrm{D}, 11 \mathrm{D} 21$ \\
\hline 4. & Four Groups together & 0.8302 & \\
\hline
\end{tabular}

Source: own estimation based upon the methodological approach

A2 - Unemployment rate; A4 - GDP/per capita; B15 - The rate of crime per 10 000; C21 -The level of income per person in a family; D3 - The level of PIT / Private Income Tax; D7 - The level of CIT / Corporate Income Tax; D11 - The complicated Tax Law; D21 - The level of excise.

Table 2

\section{Values of Factors in the Regression Model (the Polish Case)}

\begin{tabular}{|l|c|c|c|c|c|c|c|c|c|c|}
\hline $\mathbf{Y}$ & $\mathbf{R}^{\mathbf{2}} \mathbf{\gamma}$ & $\mathbf{a 0}$ & $\mathbf{A ~ 2}$ & $\mathbf{A ~ 4}$ & B 15 & C 21 & D 3 & D 7 & D11 & D 21 \\
\hline 2. & 0.7782 & -2.322 & 0.655 & -0.342 & 0.281 & 0.422 & $\mathrm{n} / \mathrm{a}$ & 0.582 & 0,511 & $\mathrm{n} / \mathrm{a}$ \\
\hline 3. & 0.8311 & -2.541 & 0.656 & -0.221 & 0.174 & $\mathrm{n} / \mathrm{a}$ & 0.531 & $\mathrm{n} / \mathrm{a}$ & 0,501 & 0.544 \\
\hline 4. & 0.8302 & -2.552 & 0.654 & -0.227 & 0.172 & 0.327 & 0.488 & 0.512 & 0,513 & 0.522 \\
\hline
\end{tabular}

Source: own estimation based upon the methodological approach

In Poland, the most important factors fostering shadow economy performance relate to economic situation/ unemployment rate, GDP per capita and the level of income per person in a family. Strong impact of the level of taxation is noticed, especially to PIT, CIT and Excise taxes. The complicated tax system is also a very important factor encouraging shadow economy's vitality. The crime rate was statistically important. Crime is always connected with shadow economy activity. Quite similar results were achieved in Lithuania.

Factors Fostering Shadow Economy Level in Lithuania

Table 3

\begin{tabular}{|c|c|c|c|}
\hline No. & Grouped variables & The value of adjusted $\mathbf{R}^{2}>\mathbf{0 . 7 5}$ & Factors \\
\hline 1. & Group 1, Group 2, Group 3, Group 4 only & n/a & 0.7611 \\
\hline 2. & Group 1 Group 2 Group 3 together & 0.8001 & A2, A4, B15, C21, D7, D8, D11 \\
\hline 3. & Group 2 with Group 3 and 4 together & 0.8177 & A2, A4, B15, D3, D8, D11, D21 \\
\hline 4. & Four Groups together & $\begin{array}{c}\text { A2, A4, B15, C21, D3, D8, D7, } \\
\text { D11, D21 }\end{array}$ \\
\hline
\end{tabular}

Source: own estimation based upon the methodological approach 
Values of Factors in the Regression Model (the Lithuanian Case)

\begin{tabular}{|l|c|c|c|c|c|c|c|c|c|c|c|}
\hline $\mathrm{Y}$ & $\mathrm{R}^{2}>$ & $\mathrm{a} 0$ & $\mathrm{~A} 2$ & $\mathrm{~A} 4$ & $\mathrm{~B} 15$ & $\mathrm{C} 21$ & $\mathrm{D} 3$ & $\mathrm{D} 7$ & $\mathrm{D} 8$ & $\mathrm{D} 11$ & $\mathrm{D} 21$ \\
\hline 2. & 0.7611 & -2.991 & 0.599 & -0.411 & 0.301 & 0.502 & $\mathrm{n} / \mathrm{a}$ & 0.432 & 0.311 & 0,601 & $\mathrm{n} / \mathrm{a}$ \\
\hline 3. & 0.8001 & -2.221 & 0.548 & -0.332 & 0.276 & n/a & 0.531 & $\mathrm{n} / \mathrm{a}$ & 0.309 & 0,561 & 0.511 \\
\hline 4. & 0.8177 & -2.009 & 0.5443 & -0.311 & 0.243 & 0.331 & 0.488 & 0.407 & 0.299 & 0,553 & 0.409 \\
\hline
\end{tabular}

Source: own estimation based upon the methodological approach

Like in Poland, the most important factors fostering shadow economy performance in Lithuania relate to the taxation system. In this group, one more factor (in addition to the ones observed in Poland) was noticed, which was the duration of control carried out by the Tax Office. Same as in Poland, the complicated law system is a crucial factor influencing the development of shadow economy in Lithuania. General macroeconomic situation and income per family member occupy an important place as factors influencing shadow economy in Lithuania. The crime rate in Lithuania, higher than in Poland, is recognized as a factor stimulating shadow economy in that country.

\section{Discussion}

Factors fostering shadow economy performance in Lithuania and Poland show an astounding relationship. One possible reason is the fact that both countries had belonged to the same economic (central planned one) regime before 1989. In 1989, the former communist countries embarked on the transition from a commanded, centrally planned economy to a market economy. Those economies were strongly focused on domestic and regional markets rather than international ones (Elliot,1995). Lithuania failed to achieve radical stabilization and liberalization in early years of transition, whereas Poland instantly introduced harsh economic reforms, known as the shock therapy (Balcerowicz \& Gelb, 1994). Because centrally planned economy proved to be very inefficient, shadow economy was generated by market gaps, low standard of living, macroeconomic chaos, corruption, and criminality (Cottarelli \& Blejer, 1991). Additionally, shadow economy was widely accepted in the society. That is why, it was quite difficult to lower its level (Bruno, 1988, Buszko, 2016). The real economic mechanism was reflected in the reform process and implementation of market-oriented economy. Shadow or underground economic activity is often an unavoidable consequence of economic movement. The extent of shadow economy in selected countries depend on many variables that can be predicted by the government, and on factors that are beyond any control (Herwartz \& Theilen, 2007). Due to this fact the shadow economy activity faces common roots. Finally, the same shadow economy category and its level (as the share of GDP) arose in Lithuania and in Poland. One of the most important concerns contributing to shadow economy are the income situation and standard of living conditions. Although they have been improving, there is still much room for enhancement. In Poland, the yearly average equalized disposable income was definitely lower in rural areas than in urban areas (respectively: PLN 24.702 and 33.076) in previous years (before 2018). There was also a difference in its amount among the categories of cities by their size. The lowest disposable income was in the smallest cities, i.e. below 20 thousand residents (PLN 30.026) and the highest was in the largest cities (PLN 40.577). The maximum increase in the average yearly equalized disposable income between 2014 and 2017 was recorded in cities below 20 thousand residents (approx. PLN 5 thousand). In those cities, there was also the highest growth rate $(120.0 \%)$. In cities with the population between 100 and 499 thousand and in rural areas, the disposable income increased the least, i.e. by about PLN 3.3 thousand. However, the growth rate of income for rural areas was slightly higher $(115.0 \%)$ than in the aforementioned category of cities (111.0\%) (SILC survey, 2018). Furthermore, the disposable income in PPS (Purchasing Power Standard, which is a joint conventional currency unit applied in the European Union for converting aggregated economic data for the purposes of spatial comparisons among the Member States) in Poland in 2017 was 12 695, and Poland was the $20^{\text {th }}$ place among the 28 EU countries. Poland was one of 15 countries with the income below the average income in the EU, lower by 6,000 PPS. Lower disposable income was characteristic for 7 former Eastern Bloc Countries (Lithuania, Slovakia, Latvia, Croatia, Bulgaria, Hungary, Romania) and Greece. The difference between the disposable income from the wealthiest country, i.e. Luxembourg and the income of people living in Poland was more than 20,000 PPS (SILC survey, 2018). Disposable income in PPS for Lithuania in 2018 was 12061 PPS. Such a situation makes impact on shadow economy's development. It should be noted that nearly 30 years have passed since the market-oriented reforms were introduced and the economic gap between Western Europe and Poland or Lithuania has not been narrowed so much. The highest differentiation of income was characteristic for Lithuania (with an increase from 6.1 in 2008 to 7.3 in 2017). Additionally, the size of the population at risk of poverty or social exclusion in Lithuania is relatively large, even though the number of people at risk of poverty and social exclusion fell to 804,000 in 2014. This was due to the economic recovery and some policy measures, but the figure still remained above the pre-crisis level. Lithuania continues to be one of the most unequal countries in the European Union (Lithuania Report, 2018). The inequalities of the disposable income make space for shadow economy. Another very important aspect is connected with crime. Although the number of criminal acts in Poland decreased from 1.4 million in 2002 to 0.82 million in 2018 , the economic crime became problematic. The level of economic criminal acts increased, reaching 0.2 million cases in 2018. The upsurge of economic crime rate can be explained by the increase of the level of education. More citizens have been granted the access to higher education. Meanwhile the number of people with primary and secondary education level has been declining (Kadziolka, 2016). It is arguable that well educated people are aware of law consequences and are not willingly to violate the institutional order. Those people can 
exploit law gaps and facilitate shadow economy motion in the perfect way. Moreover, the development of new technologies also fosters economic crime. Some types of crime (e.g. money laundering, employing crypto currencies mode) can be moved to the internet very easy. This type of activity is not only tightly connected with economic crimes, but it is difficult to trace. That why ironically numerous well-educated people are involved in economic crimes.

In Lithuania, the crime rate fell during the 2005-2007 period, but this trend was reversed in 2008 , coinciding with the onset of the economic crisis. A total of 84715 crimes were registered in 2013, which constitutes a $5.6 \%$ decrease in the crime rate relative to 2005 . However, the year's crime rate per 100,000 people ( 2866 ) was the highest in the 2005 2013 period due to the country's decreasing total population level (Lithuania Report, 2018). A very positive situation is noticed regarding organized crime groups both in Poland and Lithuania. Many groups in Lithuania have been broken or dismantled. Members of these groups (in Kaunas, Vilnius, Klaipeda, Panevezys) have been arrested and imprisoned (Gutauskas, 2011). A similar situation has occurred in Poland. Nearly all important organized crime groups have been destroyed. Organized crime groups (OCG) play a very important role in shadow economy's development. Their activity is permeated with the necessity of illegal economic acts. In this way, OCG create a big space for shadow economy's progress. The Polish tax law seems to be logical and similar to that in other EU countries, but in real terms it is regarded as complicated and contradictory. Moreover, Polish Tax Law cannot stop VAT frauds significantly. According to reports by the European Commission, the Polish VAT gap grew sharply between 2006 and 2011, rising from $0.4 \%$ to $1.5 \%$ of GDP. In 2012, its size peaked at PLN 43.1bn. In 2016, it fell to PLN 34.9bn. (Polish Economic Institute, 2019).

The Polish Ministry of Finance has worked on legislation that has the following aims:

- to improve the current patchwork system through the introduction of (still excessively vague) regulations to bring Poland in line with the current global trend,

- to tighten the leaking tax system through the introduction of a General Anti-Avoidance Rule (GAAR) and controlled foreign corporations (CFC) rules,

- to supervise taxation of closed end-funds;

- to control transfer pricing documentation requirements and a new commercial real estate tax (Whitehead, 2018).

The Lithuanian Tax Law system aims to be stable, simple and business-friendly. However, there are law gaps that can be exploited by shadow economy executives. The taxation of controlled foreign entities ("CFC income") is an example. Under the current legislation, a Lithuanian company having established a subsidiary, for example in a free economic zone in Belarus, that exports most of its output to other CIS States would be subjected in Lithuania to corporate income tax on the income of the subsidiary. This is clearly not a typical tax evasion or tax optimization case, but still it might affect the budget revenue. Some transactions could be unrecorded. Therefore, the current taxation regime should be reviewed and improved (Investors' Forum Outlook, 2011). In 2015, the taxation gap in Lithuania was $11 \%$ of GDP (Raczkowski \& Mroz, 2018). Undoubtedly, such a situation in Lithuania might show distortions to the principle of equity in taxation. Horizontal equity requires that taxpayers with a similar ability to pay taxes pay the same or at least similar taxes, while vertical equity recommends that taxpayers with a superior ability to pay taxes pay more taxes, according to their financial standing situation. (Fiscalis, 2106). In a way, such a situation applied to Poland as well.

\section{Conclusions}

The theoretical approach evaluates all $\underline{95}$ factors assumed in this research as important and influencing shadow economy performance. However, this empirical study implicates the factors specifically fostering shadow economy activity in Poland and Lithuania. They applied to both Lithuania and Poland. Among the features clustered in the first group, GDP per capita and unemployment rate were crucial ones. Whenever an improved economic situation is noticed, there is less space for shadow economy performance. Good economic situation is manifested by high GDP and low rate of unemployment. Hence, a good economic situation affects the level of income per family member as well. A higher level of income means less impulse for shadow economy development. Crime level is quite often omitted in research on shadow economy. However, this study shows that the crime level in both Lithuania and in Poland supports illegal economics activity. It fosters a more widespread acceptance of shadow economy performance as less dangerous for the society than crime. Moreover, sooner or later criminals will seek cooperation with shadow economy animators. This is due to the fact that villains will need money for survival. Another issue is money laundering. Criminal money should be legalized. The taxation system appears to be a crucial factor for shadow economy expansion. The level of taxes and, more importantly, the complicated and contradictory law regulations come into play. This means that Lithuania and Poland face the problem of proper tax system adjustment to the business environment. Primarily, the authorities should improve law regulations, and the taxation system ought to be simplified, not contradictory (especially in Poland), and friendly to business activity. Crime rate should be reduced and the overall economic situation needs to be improved. Unless these circumstances are not changed, the shadow economy in Lithuania and Poland will unfortunately remain on the high level.

\section{References}

Andersen, T., M., Holmstrom, B., Honkapohja, S., Korkman, S., Soderstrom, H., T., \& Vartiainen, J. (2007). The Nordic Model. Embracing globalization and sharing risks, The Research Institute of the Finnish Economy (ETLA), Taloustieto Oy

Balcerowicz, L., \& Gelb, A. (1994). Macropolicies in Transition to a Market Economy: A Three-Year Perspective, paper presented at the World Bank's Annual Conference on Development Economics, Washington, D.C. April 28 \& 29, 21-45 
Bruno, M. (1988). Opening Up: Liberalization with Stabilization [in:] R. Dombusch, F. Leslie C.H. Helmers (eds.) The Open Economy, EDI Series in Economic Development. New York: The World Bank \& Oxford University Press

Buehn A., Lessmann, Ch., \& Markwardt, G. (2013). Decentralization and the shadow economy: Oates meet AllinghamSandmo. Applied Economics, 45, 2567-2578. https://doi.org/10.1080/00036846.2012.671923

Buehn A., Dell'Anno R., \& Schneider F. (2012). Fiscal illusion and the shadow economy: Two sides of the same coin?, MPRA Paper 42531,1-32, https://mpra.ub.uni-muenchen.de/42531/

Buszko, A. (2019). Kulturowe uwarunkowania powstawania i funkcjonowania szarej strefy. UWM. Olsztyn

Buszko, A. (2016). Mechanizmy szarej strefy. CeDeWu. Warszawa

Cassel, D. (1984). The growing shadow economy: Implications for stabilization policy, Intereconomics, ISSN 0020-5346, Verlag Weltarchiv, Hamburg, 19 (5), 219-225. https://doi.org/10.1007/BF02928341

Cook, P. (1986). The demand and supply of criminal opportunities. Crime and Justice, 7, 1-27.https://doi.org/10.10 86/449111

Cottarelli, C. I., \& Blejer, M. I. (1991): Forced Savings and Repressed Inflation in the Soviet Union: 1986-1990, Some Empirical Results, IMF Working Paper, Washington, D.C. 39(2), 1-31. https://doi.org/10.2307/3867059

Curti D., Ce S., Ridgeway W., Chaloupka, F., \& Fong G. (2015). The use of legal, illegal and roll-your-own cigarettes to increasing tobacco excise taxes and comprehensive tobacco control policies: findings from the ITC Uruguay Survey. Tobacco Control 24 (3), 1-8. https://tobaccocontrol.bmj.com/content/24/Suppl_3/iii17; https://doi.org/10.1136/ tobaccocontrol-2014-051890

Dalio, R., Kryger, S., Rogers, J., \& Davis, G. (2017). Populism: The Phenomenon. Bridgewater Daily Observations. March 3 (22), 1-61, https://economicprinciples.org/downloads/bw-populism-the-phenomenon.pdf

Dell'Anno, R. (2007). The Shadow Economy in Portugal. An Analysis with the MIMIC Approach. Journal of Applied Economics, 10(2), 253-277. https://ucema.edu.ar/publicaciones/download/volume10/dellanno.pdf; https://doi.org/10.10 80/15140326.2007.12040490

Dell'Anno, R., Gomez-Antonio, M., \& Pardo, A. (2007). The shadow economy in three Mediterranean countries: France, Spain and Greece. A MIMIC approach. Empirical Economics, 33(1), 51-84. https://doi.org/10.1007/s00181-006-0084-3

De Soto, H. (2000). The mystery of capital: why capitalism triumphs in the west and fails everywhere else. Basic Books, New York

Domadenik, P., Prasnikar, J., \& Svejnar, J. (2016). Political Connectedness, Corporate Governance, and Firm Performance. Journal of Business Ethics, 139, 411-428. https://www.jstor.org/stable/44164231; https://doi.org/10.1007/s10551-0152675-4

Dreher, A., \& Schneider, F. (2006). Corruption and the Shadow Economy: An Empirical Analysis, CESifo Working Paper Series 1653, CESifo. https://EconPapers.repec.org/RePEc:jku:econwp. https://doi.org/10.2139/ssrn.878669

Elliot, J. E. (1995). Disintegration of the Soviet politico-economic system. International Journal of Social Economics, 22 (3), 31-60. https://doi.org/10.1108/03068299510146745

Enste, D. H. (2010). Regulation and shadow economy: empirical evidence for 25 OECD-countries. Constitutional Political Economy, 21, 231-248. https://doi.org/10.1007/s10602-009-9081-9

Fiscalis Tax Gap Project Group. (2016). The Concepts of Tax Gap. Report on VAT Gap Estimations. Brussels. March

Frey, B., \& Weck, H. (1982). Estimating the Shadow Economy: A 'Naive' Approach". Oxford Economic Papers, 35, (1), 2344. https://www.jstor.org/stable/2662921; https://doi.org/10.1093/oxfordjournals.oep.a041582

Gobbi, G., \& Zizza, R. (2012). Does the underground economy hold back financial deepening? Evidence from the Italian credit market. Journal of Applied Economics, 31(1), 1-29. https://www.researchgate.net/publication/239808329

Giuliano P, \& Ruiz-Arranz, M. (2009). Remittances, financial development and growth. Journal of Development Economy, 90(1), 144-152. https://econpapers.repec.org/RePEc:eee:deveco:v:90:y; https://doi.org/10.1016/j.jdeveco.2008.10.005

Gutauskas, A. (2011). Economic Crisis and Organized Crime in Lithuania. Jurisprudence, 18(1), 303-326, https://www.ceeol.com/search/article-detail?id=946832

Herwartz, H., \& Theilen, B. (2007). Does EU Financing System Contribute to Shadow Economy. Economics \& Politics, 25 (2), 135-161. https://doi.org/10.1111/ecpo.12007

Investors' Forum Outlook. (2011). Lithuania. Making the Tax System Better for Everyone. September. Ernst\&Young

Kabaj, M. (2009). Praca nierejestrowana we wspolczesnej literaturze ekonomicznej, Polityka Spoleczna, 10, 3-10 https: YADDAbwmeta1.element.ekon-element-000165007031

Katsios, S. (2006). The Shadow Economy and Corruption in Greece. South-Eastern Europe Journal of Economics, 1, 61-80, http://www.asecu.gr/Seeje/issue06/katsios.pdf 
Kadziolka, K. (2016). Analysis of the crime rate in Poland in spatial and temporal terms. Central and Eastern European Journal of Management and Economics 4, (1), 81-96, https:YADDAbwmeta1.element.desklight-f69f4110-50bb-4829b9b2-0129e4a2dd7e

Lampe, K. (2015). Big business: scale of operation, organizational size, and the level of integration into the legal economy, as key parameters for understanding the development of illegal enterprises. Trends in Organized Crime 18, $289-310$. https://doi.org/10.1007/s12117-015-9255-y

Lithuania Report. (2018). Sustainable Governance Indicators 2018. Bartelsmann Stiftung

Loayza, N, Oviedo, A. M., \& Serven, L. (2006). The impact of regulation on growth and informality, cross-country evidence. [in:] Guha-Khasnobis B., Kanbur R., Ostrom, E. (eds). Linking the formal and informal economy, concepts and policies. Oxford University Press, Oxford. https://doi.org/10.1093/0199204764.003.0007

Maloney, W., \& Mendez, J. (2004). Measuring the impact of minimum wages. Evidence from Latin America, Law and Employment: Lessons from Latin America and the Caribbean. University of Chicago Press. https://doi.org/10.72 08/chicago/9780226322858.003.0002

Masiukiewicz, P., \& Dec, P. (2015). Economic Crime and Determinations of the Black Market Loans. Transformations in Business \& Economics, 14(2), 117-132, https://www.researchgate.net/publication/282948619_Economic_crime_and _determinants_of_the_black_market_loans

Polish Economic Institute (2019). VAT Reducing the VAT gap: lessons from Poland. Causes, Remedies, Outlook. February, Warsaw

Putnins, T. J., \& Sauka, A. (2015). Measuring the shadow economy using company managers. Journal of Comparative Economics, 43(2), 471-490. https://doi.org/10.1016/j.jce.2014.04.001

Raczkowski, K., \& Mroz, B. (2018). Tax gap in the global economy. Journal of Money Laundering Control 21(4), 545554.https://doi.org/10.1108/JMLC-12-2017-0072

Rosser Jr, J. B., Rosser, M. V., \& Ahmed, E. (2000). Income inequality and the informal economy in transition economies. Journal of Comparative Economics, 28, 156-171. https://doi.org/10.1006/jcec.2000.1645

Schneider, F., \& Enste, D. (2000). Shadow Economies Around the World - Size, Causes, and Consequences. Journal of Economic Literature 38(1), 77-114. https://doi.org/10.1257/jel.38.1.77

Sekliuckiene, J. (2017). Factors leading to early internationalization in emerging Central and Eastern European economies. Empirical evidence from new ventures in Lithuania. European Business Review, 29(2), 219-242. https://doi.org/10.11 08/EBR-12-2015-0158

SILC survey of 2017. (2018). Incomes and living conditions of the population of Poland - report from the EU. Statistics Poland, Social Surveys Department. GUS. Warsaw

Wiseman, T. (2013). US shadow economies: a state-level study. Constitutional Political Economy, 24 (4), $310-335$. https://doi.org/10.1007/s10602-013-9146-7

Whitehead, S. (2018). The Tax Dispute and Litigation Review. Law Business Research Ltd. March

Zukauskas, V., \& Schneider, F. (2016). Micro Based results of shadow labour market in the Baltic States, Poland, Sweden, and Belarus. Taikomeji Ekonomika. Sisteminai Tyrimai, 10(2), 117-134. https://doi.org/10.7220/AESR.2335. 8742.2016.10.2.7

\section{Author's Biography}

Andrzej Tomasz Buszko is a professor at Institute of Economics and Finance, University of Warmia and Mazury in Olsztyn -Poland. He has sound business background working for Polish and international companies. He was first Polish commercial consul in Hong Kong. His areas of research interests are: theory of finance and management, theory of shadow economy and eliminating its negative impacts in various sectors of economy. He is author of more than 300 publications in reputed impact factor journals. Andrzej Buszko is a doctor honoris causa. ORCID: 0000-0003-0600-4646

The article has been reviewed.

Received in December 2019; accepted in January 2022.

This article is an Open Access article distributed under the terms and conditions of the Creative Commons Attribution 4.0 (CC BY 4.0) License (http://creativecommons.org/licenses/by/4.0/) 